\title{
Soberanía, campos de lucha y prácticas plurales de garantía de los derechos. Respuesta a los comentarios sobre "La ideología de la soberanía"
}

\author{
Albert Noguera Fernández \\ Universidad de Valencia \\ ORCID ID 0000-0001-9914-2970 \\ albert.noguera@uv.es
}

\section{Cita recomendada:}

Noguera Fernández, A. (2020). Soberanía, campos de lucha y prácticas plurales de garantía de los derechos. Respuesta a los comentarios sobre "La ideología de la soberanía". Eunomía. Revista en Cultura de la Legalidad, 19, pp. 579-607.

doi: https://doi.org/10.20318/eunomia.2020.5731

Recibido / received: 09/09/2020

\begin{abstract}
SUMARIO. 1. Introducción. 2. Respuesta a Sebastián Martín. 2.1. EI comentario de Martín: un alegato a favor de la rigurosidad científica y la teoría crítica. 2.2. Palabras vs. Hechos I: contradicciones metodológicas. 2.3. Palabras vs. Hechos II: contradicciones teóricas. 2.3.1. Leer a Ferrajoli desde la premisa liberal. 2.3.2. Leer a Ferrajoli desde la teoría crítica. 2.4. Sobre diagnóstico y la nueva centralidad estatal postpandemia. 2.4.1. La visión obsoleta de la forma estatal en la autonomía de lo político. 2.4.2. La confusión entre factores contrarestantes y factores altertendenciales. 2.4.3. El plan de reconstrucción postpandemia de la UE. 3. Respuesta a Ricardo Cueva. 3.1. Las insinuaciones sin argumentar. 3.2. El monoteísmo liberal. 3.2.1. El espacio sociopolítico y la lucha de sujeto, objeto y práctica.

3.2.2. Revolución vs. reforma.
\end{abstract}




\section{Introducción}

Quisiera, para empezar, expresar mi más sincera gratitud, por un lado, a la revista Eunomía por dedicar la sección Book Forum de su número 19 al libro La ideología de la soberanía y, por otro lado, a los profesores Sebastián Martín y Ricardo Cueva por haber dedicado parte de su tiempo a leer y escribir un comentario sobre mi libro (Noguera, 2019). En la sociedad del tiempo escaso y la avalancha de publicaciones en que vivimos, que haya personas que dediquen momentos a leerte y pensarte merece agradecimiento. Responderé primero al comentario de Sebastián Martín y, seguidamente, al de Ricardo Cueva.

\section{Respuesta a Sebastián Martín}

El comentario de Sebastián Martín (2020) está bien estructurado y contiene halagos y objeciones claramente argumentados. Se trata de un comentario de 20 páginas que demuestra una lectura seria del libro. Conociendo al profesor Martín, no podía ser de otra manera.

Este se divide en una primera parte dedicada a realizar una síntesis del libro y señalar las aportaciones y logros del mismo y una segunda parte dedicada a sus flaquezas, que divide en: metodológicas, de diagnóstico, argumentativas y aplicativas.

No puedo más que agradecerle los elogios de la primera parte y pasar, directamente, a responder las críticas de la segunda. De ellas, como indicaré seguidamente, solo puedo aceptar algunas y discrepar profundamente con otras.

2.1. El comentario de Martín: un alegato a favor de la rigurosidad científica y la teoría crítica

Sebastián Martín empieza su comentario haciendo referencia a Pierre Bourdieu y a su reflexión acerca del papel que deben desempeñar los intelectuales. La referencia al francés le sirve para dedicar sus primeras páginas a hacer un alegato en favor de la obligatoriedad de todo profesor comprometido con su sociedad de tener que combinar en su obra, en igual proporción, rigurosidad científica y teoría crítica.

A partir de esta introducción, Martín formula su primera crítica al libro. Este objeta que, en determinados apartados, al desarrollarse la historia del pensamiento jurídico-político y al formularse determinadas representaciones historiográficas no hay la rigurosidad ni la precisión historiográfica que, desde el punto de vista del historiador, se requeriría. Esta crítica metodológica la formula en dos partes:

Una primera, ubicada en el punto 4.1 (flaquezas metodológicas) del comentario, donde critica que el libro reproduce lo que Adorno censuraba como subjetividad creadora, es decir, ubicar en determinados autores y sus obras el punto de referencia para hacer mención a transfiguraciones históricas concretas de la realidad social. Por ejemplo, ubicar en Jean Bodin y a su obra Los seis libros de la república o en la obra de los contractualistas los momentos de transformación del concepto moderno de soberanía, entre otros. Frente a ello Martín escribe: «A mi juicio, no hay proceso de transformación operada en la estructura de las relaciones sociales que no complique, en diversa proporción y de forma inextricable, factores culturales y materiales. En los intervalos de cambio suele presenciarse la generalización ascendente de una cosmovisión cultural que logra ir desplazando de la escena a la concepción anteriormente predominante, pero también una concatenación de factores 
en el plano de las relaciones socioeconómicas que propicia -que convierte en plausible y aceptable- dicha hegemonización cultural paulatina».

$\mathrm{Y}$, una segunda, ubicada en el último apartado, punto 5 , de su comentario al que denomina «historia sobrante», donde se detiene en señalar varias imprecisiones historiográficas detectadas en el libro referentes a la época clásica y moderna.

Sobre ello, poco tengo que añadir más que aceptar la crítica. Respecto a la primera parte, el mismo Sebastián Martín formula lo que subscribo como respuesta propia: «Se podría objetar que se trata de una simple forma de hablar o de narrar la materia expuesta, recurriendo a la metáfora o ficción de que los autores crean ideas que a su vez generan una nueva sociedad -o una nueva concepción acerca de la misma- para aludir a procesos complejos de cambio. Pero se aceptará que justo esa narrativa entra en tensión con los postulados de una obra que, para el tiempo presente, considera la teoría y al intelectual como retaguardia al servicio de la praxis emancipatoria». $\mathrm{Y}$, respecto a la segunda, reconozco también que, en diversos puntos, el libro trata lo historiográfico más como valor de cambio que como valor de uso. Es decir, más como una argumentación funcional o instrumental destinada a fortalecer las tesis defendidas por el autor que no como algo que tiene valor por sí mismo, y ello tiene el peligro de caer en la falta de rigurosidad o imprecisiones que manifiesta el recensor.

Aceptada esta crítica, debo manifestar, sin embargo, que entre lo que Martín recomienda y hace hay diferencias importantes. Ni la rigurosidad ni la teoría crítica exigida parecen ser tenidas en cuenta cuando escribe sus apartados de flaquezas de diagnóstico, aplicativas y argumentativas.

\subsection{Palabras vs. Hechos I: contradicciones metodológicas}

No puede más que sorprender que el profesor Martín centre gran parte de su texto en exigirme una rigurosidad exquisita en la escritura de los aspectos historiográficos, pero, a la vez, no aplique la misma rigurosidad en su lectura e interpretación del libro. De ahí la primera contradicción, de carácter metodológico, entre sus palabras y lo que, a continuación, hace.

Tanto en el apartado de flaquezas de diagnóstico (4.2) como aplicativas (4.4), Martín me atribuye la defensa de un proyecto que consistiría en la sustitución del Estado por una «federación de comunas solidarias». Según él, para mí -dice literalmente- sería mejor «autoorganizarse en comunas en lugar de defender las conquistas institucionales pasadas».

Una lectura rigurosa del libro permite observar en el comentario de Sebastián Martín un ejercicio de caricaturización o tergiversación de mis posiciones que le sirve para acomodar mejor la plataforma desde la que poder construir su crítica.

Cuando pone en mi boca «El autor considera un ejercicio de realismo pensar que los supuestos económicos e institucionales para la garantía universal de derechos como la sanidad, la educación, el desempleo o las pensiones se encuentran ya históricamente agotados» y que en un futuro inmediato considero que "el mejor modo de responder a la crisis sanitaria sea la autoorganización de las fuerzas sociales, pues bien cabe que ante el injustificable inmovilismo de las administraciones -en materia educativa, por ejemplo- sean los propios núcleos sociales -o familiareslos que se coordinen para satisfacer los fines desatendidos», defendiendo "su trasvase pleno a una organización comunal sin empaque alguno a día de hoy», está faltando a la verdad y ello es hacer trampas. 
Con ello, está atribuyéndome una posición inventada y que no se corresponde con la literalidad de la letra del libro. En la página 142 de La ideología de la soberanía se resume, de manera clarísima y sin lugar a confusión, la propuesta políticoconstitucional defendida a lo largo de todo el libro:

La garantía de la dignidad para las clases populares en el marco de un campo de lucha de los derechos de dialéctica compleja, donde se cruzan los ejes privado-público, procomún extractivo-cooperativo y entorno de desigualdad-igualdad, requiere de una Constitución económica conformada a partir de la combinación de los tres modelos democráticos conformadores de igualdad: el 4 (Estado social), 5 (Economía comunitaria de autogestión regulada) y 6 (Economía comunitaria de autogestión primaria), que daría lugar a lo que al final del capítulo II de este libro hemos llamado Estado redistributivo-comunal.

Ello significa, el reconocimiento, por un lado, de un fuerte sector público, retomado del Estado social, capaz de continuar ofreciendo en régimen de universalidad determinados servicios y prestaciones que, por su naturaleza, requieren necesariamente de intervención estatal y de gasto social público (sanidad, educación, seguridad social, derechos laborales, etc.). Y, por otro lado, conjuntamente con lo anterior, el reconocimiento, descentralización y transferencia de competencias y recursos (infraestructurales, técnicos, económicos, etc.) en materias tan diversas como vivienda, cultura, deporte, ambiente, etc. a las formas organizativas de lo procomún cooperativo que pueden ser de dos tipos: formas de procomún cooperativo reguladas y primarias.

Este es el proyecto político-constitucional que defiende el libro y que, además, en la página 127 se ejemplifica tomando como modelo de referencia a la Constitución venezolana de 1999, donde la creación de mecanismos jurídicos para que los Estados y los Municipios descentralicen y transfieran a las comunidades y grupos vecinales organizados los servicios que estos gestionen previa demostración de su capacidad para prestarlos, no es incompatible con un Estado fuerte que nacionaliza los recursos naturales y ofrece prestaciones sociales en régimen de gratuidad y universalidad.

No obstante, da la sensación que Sebastián Martín falsee el texto del libro porque sea la única manera que halla para evitar que muchas de las críticas que formula no resulten absurdas. Pongo dos ejemplos:

1. Solo falseando la literalidad del texto del libro puede afirmar, en el punto de flaquezas de diagnóstico, que el modelo propuesto por este «fortalece el neoliberalismo» y «liquida los sistemas públicos de educación, sanidad y pensiones aún en pie», sin que resulte ridículo.

Es innegable que junto a los hospitales y escuelas públicas existen, hoy en día, formas de autoorganización ciudadana que cubren otras necesidades no resueltas por el Estado: la PAH evitando desahucios u ocupando viviendas vacías propiedad de entidad financieras, ONGs que salvan vidas en el Mediterráneo, etc. Afirmar que si defiendes y dedicas tu tiempo a luchar en y por este tipo de espacios autoorganizados no puedes defender ni luchar por la educación o la sanidad pública es negar la necesaria complementariedad entre prácticas de garantía de los derechos en una sociedad con campos de lucha abigarrados.

Lo que no se puede es decir a toda esa gente que dedica parte de sus horas diarias a la auto-organización de redes de solidaridad colectiva que están fortaleciendo el neoliberalismo y liquidando los servicios públicos porque no están luchando por la sanidad. Porque resulta que esa gente es la misma gente que cuando los sindicatos o las mareas convocan una huelga o una manifestación contra la reforma laboral o a favor de las pensiones está en primera fila compartiendo movilización con ellos. En esto consiste entender que en una sociedad neoliberal con campos de lucha de los derechos superpuestos y donde un Estado social en 
decadencia no nos garantiza todos los derechos de la cuna a la tumba, no existe una única manera de garantizar derechos, sino múltiples. Y tan importante es, en términos de aliviar la precariedad vital inmediata que mucha gente vive en su día a día, crear formas de organización de lo colectivo para la autotutela de derechos, como defender y exigir al Estado una sanidad, una educación y un sistema de pensiones públicos y universales. $Y$, por tanto, no puede haber una jerarquización entre prácticas de garantía de los derechos ni tampoco ninguna de ellas excluye a las otras como afirma Sebastián. Todas son igual de necesarias y se complementan. Esta es la premisa defendida en el libro. Y si no, que el profesor Martín le cuente al refugiado que se está ahogando delante de las costas de España que el barco de Open Arms no puede ir a rescatarle porque apostar por ONGs o formas de auto-organización colectiva no estatal como práctica de garantía del derecho a la vida es dar alas al neoliberalismo y liquidar los servicios públicos. Que mejor se mantenga a flote unos días más mientras espera que esta función la haga aquel Estado en el que, incluso con el Gobierno más progresista al que España puede aspirar, no se sanciona administrativamente y se absuelve judicialmente a los guardia civiles que le disparan a matar con balas de goma. Ante campos de lucha de los derechos complejos, prácticas de garantía de los derechos también complejas.

2. También solo falseando la literalidad del texto del libro se puede, en el punto de flaquezas aplicativas, definir al Estado como momento igualador y único portador natural de derechos universales y a los espacios del común cooperativo como comunas o colonias icarianas caciquiles incapaces de garantizar derechos, sin que resulte absurdo.

Para Martín «solo el Estado y los organismos internacionales componen a día de hoy, al menos en potencia, un contrapeso proporcional a esa acaparación privada de recursos», a la vez que define los espacios del común cooperativo como «comunas» regidas por «cacicazgos y redes clientelares» incapaces de «lograr una eficaz protección de los derechos individuales y sociales». Como si el Estado de manera innata y por gracia divina fuera, ya de por sí, portador del reconocimiento de derechos a todos y todas y los espacios del común cooperativo no pudieran ser otra cosa más que asentamientos desinstitucionalizados de hippies sin reglas, organización ni mecanismos de control.

Es comúnmente sabido que la historia de los derechos es una historia en la que la dialéctica entre los espacios del común y estatal, donde el primero no es tan garantista ni el segundo tan poco, ha actuado, tradicionalmente, como motor del reconocimiento de los derechos.

¿O acaso, en muchos países, la ocupación y autogestión comunal de tierras por los movimientos sin tierra (democráticos y organizados) no ha sido el detonante que ha obligado al Estado a tener que aprobar leyes de reforma agraria que reconocieran el derecho de acceso a la tierra? ¿O acaso, la ocupación de viviendas por parte de movimientos de gente sin techo (democráticos y organizados) no ha obligado también, en varios Estados, a tener que regular el acceso a la vivienda? ¿O acaso, la organización de comedores paralelos y auto-gestionados por el movimiento estudiantil asambleario, destinados a boicotear el comedor universitario concesionado a una empresa privada con comida basura y precios abusivos, no ha servido para generar un problema que ha obligado a la universidad a regular la calidad y precios de los menús universitarios?

Y, lo mismo, a la inversa, ¿acaso los trabajadores de centros de trabajo, también públicos, en quiebra hubieran podido recuperarlos, pasarlos a auto-gestionar en régimen de cooperativa y evitar ir al paro o a la precariedad si no existiese una legislación estatal que permite la capitalización del paro o de las indemnizaciones de los trabajadores despedidos que deciden comprar la empresa? Solo en Murcia, entre 
2012 y 2015, 30 empresas mercantiles en quiebra fueron reconvertidas en cooperativas de trabajo por parte de los trabajadores, ¿esto no es garantizar un derecho? En Mataró, en 2011, el ayuntamiento cerró y despidió a los 35 trabajadores de la escuela municipal de música que fue recuperada por los mismos reconvirtiéndola en una cooperativa (MUSICOP) que hoy funciona de maravilla y les da trabajo. ¿Quién garantiza derechos aquí, la administración pública o las formas de organización del común?

Como digo, resulta ridículo defender estos argumentos si no es realizando un ejercicio previo de tergiversación del texto del libro. Y esto no tiene nada que ver con la rigurosidad metodológica que se recomienda.

\subsection{Palabras vs. Hechos II: contradicciones teóricas}

En el apartado de flaquezas argumentativas (4.3), Sebastián dice que la calificación de la teoría de Ferrajoli como estatista desarrollada en el libro no es del todo acertada. Afirma «no poder dejar de manifestar extrañeza» ya que según él, se trataría de una doctrina «más "sociocéntrica" que "estatólatra", pues en ella los poderes públicos, en su función de garantía e igualación, se hallan al servicio del ejercicio individual y colectivo de los derechos operado en sociedad como forma principal de su actualización. No existe en ella, por tanto, "subsunción de la sociedad en el Estado" (p. 69), sino más bien disolución de la institucionalidad estatal o internacional en la trama social, a cuya reproducción autónoma sirve». Según Martín, en la teoría ferrajoliana no hay una subsunción de la sociedad en el Estado, sino un fortalecimiento de la autonomía social.

A mí lo que me genera extrañeza es que después de iniciar su comentario con un alegato en favor de la teoría crítica, a la hora de leer a Ferrajoli afirme que la lectura acertada de su obra sea la hecha desde premisas liberales y liberalizadoras y no desde las de la teoría crítica de los derechos. De ahí que afirme que existe otra contradicción, en este caso teórica, entre lo que recomienda y lo que hace.

\subsubsection{Leer a Ferrajoli desde la premisa liberal}

El discurso liberal de los derechos parte de la premisa de que los derechos surgen de la sociedad (derechos naturales) con el objetivo de defender a esta del Estado autoritario. De acuerdo con los iusnaturalistas, no existe primero el Estado y después los derechos, sino a la inversa, primero existirían los derechos, propios del ámbito de la sociedad, y después el Estado.

En este orden de primero los derechos y luego el Estado, la Constitución de los derechos es una abstracción que no existe como entidad real, su forma real se materializa a través de los Poderes del Estado. Los poderes del Estado (legislativo, ejecutivo y judicial) no pre-existen a las cartas de derechos; no hay, en rigor, poderes antes de las cartas de derechos propias del constitucionalismo, es a la inversa. Los poderes se justifican, nacen y fundamentan por los derechos, con anterioridad a las cartas de derechos los poderes hubieran carecido de motivo y de justificación. En términos constitucionales, afirma tal visión, el poder legislativo nace para desarrollar conforme a la Constitución los derechos, el Ejecutivo para implementarlos y el judicial para hacerlos valer a instancia de parte interesada o, de ser necesario, frente a los otros dos poderes juntos o por separado. Su función debe ser estar al servicio de los derechos. Por tanto, de acuerdo con esta lógica, se partiría, repito, de la idea de que no existe primero el Estado y después los derechos, sino a la inversa, primero existirían los derechos (que se corresponderían al campo de la sociedad) y después el Estado. 
A partir de esta premisa se lee la propuesta ferrajoliana de funcionalización de todos los poderes del Estado a la garantía de los derechos (propios de la sociedad), como una subordinación del Estado a los derechos, esto es, a la sociedad. Es decir, no como una subsunción de la sociedad en el Estado, sino como una doctrina que pone a la sociedad-derechos en el centro. Por eso Martín dice que es "sociocentrista», y el Estado, al garantizar o ponerse al servicio de tales derechos, no haría más que garantizar y permitir la supremacía de la sociedad, léase la reproducción de la autonomía social frente al poder estatal.

Esta lectura de la doctrina del autor italiano que hace Sebastián Martín y que diría no solo que es liberal sino, incluso, excesivamente liberalizadora de Ferrajoli, no es aceptable si se parte de la teoría crítica de los derechos como premisa.

\subsubsection{Leer a Ferrajoli desde la teoría crítica}

A diferencia de la teoría liberal, la teoría crítica de los derechos invierte la premisa inicial. Según esta, los derechos subjetivos no son un discurso que surge de la sociedad para defenderse del Estado, como cuentan los iusnaturalistas, sino todo lo contrario. Son un discurso que surge del Estado (derechos subjetivos positivos y Estado liberal surgen de la mano) para defenderse de la sociedad.

Al estructurar, con la aparición del Estado liberal moderno y sus cartas de derechos, el sistema de relaciones sociales alrededor del discurso de los derechos subjetivos, las burguesía crea un modelo donde los conflictos sociales ya no se resuelven en términos de clase en el seno de la sociedad, sino en términos de individuo-ciudadano en el seno del Estado, reelaborando el conflicto y desactivando la amenaza contra la propiedad.

El queridísimo Oscar Correas lo explicó brillantemente. Los derechos subjetivos modernos y sus garantías otorgan derechos o facultades a los ciudadanos, les dan permiso para acudir al Estado o a un funcionario público, por ejemplo a un juez mediante una demanda, y establecen la obligación de este funcionario público de convertir en eficaz el derecho o la directriz de política pública demandada. Las relaciones entre los individuos quedan entonces mediadas por el Estado. Esta es una de las notas definitorias del derecho moderno.

En el mundo romano, por ejemplo, el ciudadano se dirigía al pretor para que este dijera si la acción que iba a cumplir contaba con el apoyo de la Civitas. El pretor le «daba acción» y el ciudadano realizaba por sí mismo la tarea de dirigirse a su deudor y cobrar la deuda o recobrar la cosa. En la modernidad, el ciudadano tiene prohibido dirigirse directamente a su deudor, esto es interpretado de manera negativa como «tomarse la justicia por su mano», pues debe ser siempre un funcionario público el que producirá las acciones necesarias para satisfacer las demandas del primero (Correas, 2003, p. 30).

En consecuencia, el derecho moderno, al convertir al individuo en "ciudadano», expropia a los individuos de su relación directa con el resto de miembros de la sociedad civil. La única manera que el ciudadano tiene para hacer efectivo un derecho y propiciar una situación de igualación es acudiendo al Estado o funcionario autorizado para que resuelva el problema.

Las clases populares no tienen ninguna oportunidad de dirigirse directamente a sus enemigos de clase en el seno de la sociedad civil. Lo moderno del derecho moderno consiste en haber organizado la mediatización de los integrantes de la sociedad civil a través de una ficción que llamamos Estado. El Estado no existe como 
entidad, este no es más que la voz de sus funcionarios. Los ciudadanos han sido expropiados de cualquier otra forma de hablar y relacionarse entre ellos que no sea a través de un tercero, el Estado. Ello tiene consecuencias importantes.

Una es la desaparición de la responsabilidad de la clase dominante tras la mediación del derecho. Como el individuo precario y explotado, devenido ciudadano, se ve obligado a dirigirse a funcionarios estatales para reclamar sus aspiraciones o derechos, queda oculto el sujeto central de esta dramática situación: la clase dominante. Los detentadores de la mayor parte de la riqueza no aparecen en escena. El discurso del derecho permite su ocultamiento. El Estado siempre se les aparece como responsable inmediato. Este actúa como muro entre las clases, como mediación entre compañeros y enemigos de sociedad civil. El discurso del derecho moderno permite el ocultamiento del capitalista y, por tanto, del enemigo y culpable de la miseria de la mayoría, lo que queda patente, por ejemplo, en la concepción y diferenciación de la huelga como el simple ejercicio de un derecho (huelga laboral) y no como una acción política contra el enemigo de clase (huelga política).

Otra es la destrucción de las formas societales mediante las cuales los individuos o grupos sociales se relacionan entre sí y, por tanto, se elimina toda posible relación conflictiva directa entre clases o grupos que pongan en peligro las propiedades de los más favorecidos. Cualquier conducta subversiva de acción directa que no pase por la mediación «racional» del Estado es antijurídica y prohibida (Correas, 2003, p. 32).

Si partimos de esta teoría como premisa, y ello es lo propio de la teoría crítica de los derechos, la propuesta ferrajoliana de convertir los derechos subjetivos en el centro axiológico y articulador de todas las relaciones sociales, capturando cualquier poder salvaje que pueda aparecer en la sociedad para incluirlo en la lógica de los derechos, lo que hace no es, como dice el profesor Martín, otorgar autonomía o reconocer supremacía al espacio social donde los conflictos se resuelven en términos de clase, por vía directa y sin intermediarios, sino todo lo contrario, llevar a cabo una subsunción de todas las relaciones sociales a la lógica de ciudadanía, o lo que es lo mismo, a la lógica de mediación de las relaciones por vía de la acción «racional» del Estado. Es decir, canalizar y subsumir los conflictos de la sociedad hacia el interior de la intermediación estatal o ciudadanía. De ahí que, leída desde la teoría crítica y no de la liberal, la de Ferrajoli no pueda ser más que una doctrina estatista, no sociocentrista.

Tampoco aquí la lectura de Ferrajoli que hace el profesor Martín tiene nada que ver con la teoría crítica que recomienda.

\subsection{Sobre diagnóstico y la nueva centralidad estatal postpandemia}

Volviendo, de nuevo, al apartado referente al diagnóstico, Martín critica la diagnosis histórica sobre la que se construye la propuesta político-constitucional contenida en él. Esto es, la idea según la cual nos dirigimos hacia un futuro más neoliberal y con un cada vez mayor debilitamiento de lo público-estatal. El recensor califica este pronóstico de estar construyendo una filosofía de la Historia hecha de leyes objetivas catastrofistas y afirma no solo que esta inercia no tiene, necesariamente, por qué ser cierta, que es posible invertirla, sino que además considera que esta inversión salvadora ya estaría empezando a llegar: «el comentario presente -señala- cuenta con la ventaja relativa de haberse escrito durante la rotunda emergencia sanitaria que supone la pandemia que padecemos. Y parece que la respuesta institucional a la misma en Europa ha vuelto a colocar sobre el tapete una centralidad estatal». 
Frente a esta posición de Sebastián, me reafirmo en que, desgraciadamente, la dirección hacia la que vamos es la de un debilitamiento de la función política garantista del Estado. Esto no significa la desaparición del Estado, mientras exista capitalismo existirán Estados, ninguno de los dos puede sobrevivir sin el otro, pero sí implica un cambio claro de sus funciones políticas en un sentido neoliberal. sentidos:

Mi posición respecto la argumentación de Sebastián Martín es firme en dos

- Cuando dice que la tendencia histórica no necesariamente debe ser así, sino que, hoy, es posible invertir la Historia, lo que está haciendo es partir de una visión obsoleta de la forma estatal basada en la autonomía de lo político, que le lleva a confundir los factores contrarrestantes con factores altertendeciales.

- Y cuando dice que la respuesta europea a la pandemia está siendo volver a colocar la centralidad estatal en el tapete es porque, simple y llanamente, no ha hojeado el documento de conclusiones del Consejo Europeo de 17 a 21 de julio de 2020 donde se fija el llamado Plan de reconstrucción postpandemia de la UE. De nuevo, apelo a lo que entiendo como falta de rigor.

\subsubsection{La visión obsoleta de la forma estatal en la autonomía de lo político}

Con su argumentación, Martín sigue pensando la forma estatal, en primer lugar, como unidad autónoma de gobierno interno de la comunidad y, en segundo lugar, como institucionalidad procesadora del conflicto social en términos de derechos.

Para él, el Estado es la forma de constitución y gestión interna de la vida política que se ejerce a través de mecanismos puramente internos como son la ciudadanía y su progresiva ampliación, mediante las generaciones de derechos, a los nacionales. En este sentido, el Estado cobra sentido como espacio soberano de separación del exterior en su papel organizador del interior. El Estado debe entenderse aquí desde su adentro territorial, como unicidad interna, como una frontera de separación del poder interno y otorgador del monopolio de gobierno.

Además, sigue pensando el Estado como aparato procesador del conflicto social interno en términos de ruptura constituyente o de ampliación de derechos. Es decir, como espacio en cuyo interior la presión social es reelaborada siempre por el Estado en forma de proceso constituyente o de ampliación de derechos subjetivos universales. El momento normativo se percibe como aquel momento de mediación entre autoridad y sociedad en el que se da la traducción del conflicto social en más derechos subjetivos.

En tal contexto, los sujetos políticos de izquierda (partidos, sindicatos, movimientos sociales, etc.), en tanto sujetos incluidos en el conjunto de procesos y prácticas nacionales de conflicto social, podrían presionar al Estado y, en función de la correlación de fuerzas, alterar los escenarios socioeconómicos, conformándose en un factor altertendencial.

Sin embargo, ninguno de estos dos rasgos que describen la posición de Martín caracterizan hoy la forma estatal del siglo XXI, cuya naturaleza es totalmente distinta.

En las últimas décadas del siglo XX, los teóricos de la escuela de la regulación (Aglietta, 1979; Boyer, 1992; Lipietz, 1986) reflexionaron acerca de la relación entre capitalismo y Estado, acuñando los conceptos de régimen de acumulación y modo de regulación. El primero da cuenta de las propias dinámicas económicas constituyentes 
de cada una de las fases internas del capitalismo. $Y$ el segundo busca comprender las articulaciones específicas de lo económico con lo político y lo social en esas mismas fases. En resumen, lo que vienen a decir es que a cada régimen de acumulación, léase fase del capitalismo, le corresponde un modo de regulación particular, léase forma estatal y jurídica, que acoplada funcionalmente con el primero sostiene y garantiza su reproducción. De manera que la transición, fruto de una crisis, de una fase a otra del capitalismo (régimen de acumulación) va acompañada siempre de una transformación de la forma estatal y jurídica imperante (modo de regulación).

La forma estatal y jurídica más adecuada para la fase capitalista fordista, que estructuraba su reproducción económica alrededor de la producción y consumo nacional de mercancías, fue la del Estado en su papel de organizador intraterritorial de las tres variables que permitían la venta o conversión de mercancías en dinero: la demanda interna (mercado interno), la demanda externa (comercio internacional) y la demanda pública (contratación pública). El papel de la administración estatal era estructurar el espacio nacional interno alrededor de dispositivos institucionales orientados a generar tales variables (política fiscal, incremento de salarios, reestructuración de sectores productivos, etc.), así como de dispositivos psicológicos de inducción de la población al consumo (publicidad, marketing, etc.). El territorio interior dejó de ser solamente un soporte pasivo de la soberanía política, un mero marco geofísico de ésta, para pasar a ser un instrumento dinámico y activo de construcción del Estado como modo particular de organizar las relaciones socioeconómicas intraterritoriales.

Sin embargo, durante el último cuarto del siglo $X X$ y primeras dos décadas del XXI ocurren en el mundo un conjunto de fenómenos que han transformado radicalmente los procesos de acumulación del capital y la forma estatal y jurídica: el derrumbe del sistema de Bretton Woods y el paso a un régimen de cambios flexibles, el giro monetarista de la política económica norteamericana, la informatización de los intercambios bursátiles y la aparición con ellas del mercado de productos derivados, etc. La suma de todos estos procesos ha conformado un nuevo modelo de acumulación integral en el que la financiarización juega un papel central. La financiarización no es una distorsión de un capitalismo puro o el resultado de un golpe del sector financiero contra el capital productivo. Es, más bien, una característica estructural de la acumulación y la reproducción social bajo el neoliberalismo (SaadFilho, 2010, p. 243).

Este modelo formal de acumulación, propio del capitalismo financiero del s. $X X I$, requiere de una nueva arquitectura institucional y normativa en la que los Estados ya no pueden pensarse y entenderse como gobierno político hacia adentro, sino como estructura técnico-administrativa cuya función es actuar de conector o enlace entre la realidad nacional y el capital financiero internacional, garantizando la transferencia de recursos de la primera hacia los segundos por vía de limitación del déficit público y pago de la deuda, intereses al crédito privado, compra-venta de vivienda mediante fondos buitre internacionales, etc.

La lógica de funcionamiento de la política económica estatal se ha desconectado de los procesos y conflictos entre agentes internos para hacerse funcional al proceso de reproducción del capital en el ámbito de sistema-mundo financiero internacional. Los elementos determinantes de las políticas económicas estatales son cada vez menos lo que pasa dentro del Estado y más los vaivenes de los mercados bursátiles internacionales. En este contexto, el Estado ya no puede procesar el conflicto interno mediante la ruptura constituyente ni la ampliación de derechos en tanto que un excesivo gasto público social para implementar políticas sociales conllevaría una mala cualificación del país por parte de las principales 
agencias de rating que evalúan los estados en función de la adecuación de su presupuesto y previsión de gastos e ingresos a los criterios neoliberales. $Y$ una calificación negativa por parte de tales agencias supone, entre otras consecuencias, que los inversores no confían en destinar su dinero a una economía que no ofrece las suficientes garantías. Además, las empresas del país se ven afectadas directamente porque se exponen a ver reducida su calificación de deuda privada con la que financiar sus operaciones, produciéndose así una contracción de la economía nacional. De manera que el momento normativo tampoco actúa ya como mediación entre Estado y Sociedad, sino como cordón umbilical que lo une con el capital internacional y, sin reconocer ningún vínculo con la complejidad de la sociedad ni sus contradicciones, somete la realidad a su mandato.

Todas estas transformaciones tienen dos consecuencias importantes que desmienten la argumentación del profesor Martín.

A. La primera es que esta supuesta autonomía de lo político-estatal a la que se refiere ya no existe. Ello desmiente la visión obsoleta de la forma estatal basada en la autonomía de lo político que sostiene Sebastián Martín. Este dice: «Cada peldaño recorrido en el proceso globalizador en el terreno institucional ha sido decidido por los Estados, y nada impide que, ante la presión de las circunstancias, este camino pueda desandarse, (...) para abrir un nuevo escenario de predominio estatal». ¿De verdad cree que nada impide que, ante la presión de las circunstancias, los Estados tengan autonomía para tomar la decisión que quieran? Entonces, ¿cómo explica que después del referéndum griego de 5 de julio de 2015, donde se manifiestó un rotundo rechazo a las condiciones del rescate propuestas por la UE, el FMI y BM (difícilmente puedo imaginar un escenario con mayor «presión de las circunstancias»), el gobierno de Syriza incumpliera el resultado del referéndum y se pliegara ante las instituciones neoliberales? Según la visión de Sebastián debería interpretarse que Alexis Tsipras es un vendido que desoyó al pueblo porque teniendo autonomía para poder hacer lo que quisiese no lo hizo. ¿O será que, en realidad, esta autonomía de la que habla Sebastián Martín no existe?

O, ¿puede el gobierno de España, si así lo quisiera la mayoría de la población, «desandar el camino» y salir del euro? Sin duda, no. La fuerte integración y dependencia económica de los países de la UE provoca que la salida del euro de un país solo no implicaría para este la recuperación de su soberanía económica, ya que la propia existencia del euro ha dado lugar a una evolución en el sistema monetario internacional y a una integración productiva de las economías nacionales que provoca que la política monetaria del país en cuestión, independientemente de cuál fuese su moneda, continuaría estando sometida a los criterios monetarios hegemónicos de su área de integración económica, productiva y comercial, que no son otros que los criterios pro-finanzas y neoliberales del Banco Central Europeo (BCE) (Arriola, 2016, p. 6). Y, por otro lado, además de no conseguir el objetivo de recuperación de la soberanía económica, la salida unilateral y en solitario del euro implicaría la llegada de otras dificultades económicas añadidas con las que habría que lidiar. Por citar solo algunas: una mayor dificultad de acceso a la financiación o la multiplicación de la deuda. Las economías periféricas necesitan captar ahorro exterior para compensar su insuficiencia de ahorro interno con el cual financiar su inversión pública y privada y pagar sus importaciones. No es lo mismo financiarse con una moneda fuerte como el euro a hacerlo con una moneda más débil como lo sería la peseta, el dracma, el escudo, etc. El euro permite acceder a la financiación a un coste comparativamente más bajo porque es también más reducida la probabilidad de devaluación. La devaluación supone una mengua para el inversor extranjero, por lo cual exigirá un interés más elevado como incentivo para convencerlo de asumir este riesgo más elevado. Como señala A. Sanabria (2014, p. 32), ante la necesidad de financiación 
exterior, si tu moneda no genera suficiente confianza o muestra claros riesgos de próximas devaluaciones, como pasaría en el caso de una moneda acabada de salir del euro, el Tesoro Público se vería en la necesidad de emitir, al menos, una parte de su deuda en una moneda extranjera fuerte (dólares, euros o yenes). Esta medida permitiría acceder a mejores condiciones de financiación internacional pero, a la vez, supone un riesgo de endeudamiento en una moneda que no se controla. Además, el endeudamiento se multiplicaría exponencialmente en quedar mucha deuda en euros, mientras los ingresos serían en la nueva moneda local.

B. Y la segunda consecuencia es la conversión de la izquierda de factor altertendencial a factor contrarestante, que son dos cosas distintas y que Sebastián Martín confunde cuando afirma que es posible acabar con la tendencia histórica actual.

\subsubsection{La confusión entre factores contrarestantes y factores altertendenciales}

En un sistema donde el Estado ya no puede entenderse, exclusivamente, desde su adentro territorial, sino como una estructura técnico-administrativa que conecta la realidad nacional con los intereses de un capital financiero trasnacional y que, sin capacidad de conversión del capital ficticio en capital real, de generar empleo o asalarización, de encontrar nuevos motores de crecimiento y en el marco del colapso ecológico, solo puede reproducirse por vía de la acumulación por desposesión. En estas circunstancias resulta evidente que existe una tendencia histórica de desmantelamiento de derechos sociales connatural al sistema.

Ante esta tendencia histórica pueden existir dos opciones: la opción altertendencial o la opción contrarrestante, que son cosas distintas.

La opción altertendencial consistiría en una alternativa global capaz de revertir el modelo, cambiando la historia e invirtiendo la tendencia. Para ello, o habría que desconnectar el Estado del sistema-mundo estableciendo un sistema de autarquía absoluta, o habría que derrumbar el capitalismo mundial interconectado imperante y crear un nuevo sistema. Ninguna de las dos cosas parece factibles.

La opción contrarrestante es aquella que consiste en la posibilidad de que existan gobiernos de izquierdas o victorias sociales que permitan adoptar algunas medidas parciales, no estructurales, de mejora de las condiciones materiales de los menos favorecidos, pero que no eliminan la tendencia. De hecho, que haya una tendencia histórica de desmantelamiento de derechos sociales (que lleva ya desde inicios de los 80, más de 40 años, en curso y sigue) no significa que no puedan existir gobiernos que puedan aprobar un ingreso mínimo vital o conflictos laborales que puedan terminar en pequeñas victorias. Claro que pueden existir. Una tendencia no tiene por qué expresarse empíricamente en todo momento como tal en la realidad. Trazar tendencias no implica, nunca, negar que en el transcurso de la misma pueden existir siempre factores contrarrestantes (coyunturas concretas de crecimiento económico, normas jurídicas, medidas políticas determinadas, etc.) que, en determinados momentos y países, ralentizan la tendencia, pero eso no anula la misma. ¿O acaso cree Sebastián Martín que el aumento del salario mínimo interprofesional a 950 euros, que sin duda es un avance, ha eliminado la tendencia histórica de desmantelamiento de los derechos sociales?

El contexto actual caracterizado por la ausencia de una alternativa global hegemónica, ni teórica ni organizativa, y de Estados subordinados a los vaivenes del mercado mundial sin autonomía política real, lo único que puede hacer la izquierda en su interior es actuar de factor contrarrestante, esto es, intentar ralentizar, 
parcialmente, los efectos de la tendencia, pero no eliminar la tendencia histórica de desmantelamiento de derechos sociales. Es sobre la traza de lo que el libro considera esta tendencia histórica que se fija el escenario de partida para proponer un proyecto político constitucional alternativo para las próximas décadas, adecuado al contexto que nos toca vivir. Cuando Sebastián Martín afirma que no necesariamente ha de ser así está confundiendo los factores correstantes, que sí pueden existen y no lo pongo en duda, con los altertendenciales, que a diferencia de otros periodos históricos donde sí han existido, hoy en día, contrariamente a lo que él dice, no existen ni hay indicios de que puedan existir a medio plazo.

\subsubsection{El plan de reconstrucción post-pandemia de la UE}

Pero es que, además, como argumento de que la tendencia histórica neoliberal indicada en el libro se estaría revirtiendo, el profesor Martín dice: «parece que la respuesta institucional a la misma (la pandemia) en Europa ha vuelto a colocar sobre el tapete una centralidad estatal».

Decía antes que ello indica no haber hojeado las conclusiones del Consejo Europeo del 17 a 21 de julio de 2020, dado que una lectura de las mismas pone de manifiesto que más que volver a colocar sobre el tapete la añorada centralidad estatal, el plan de reconstrucción post-pandemia reproduce y agudiza los tres factores de desmontaje de la misma y acelera la tendencia neoliberal, lo cual fortalece mi tesis y debilita la suya. Detengámonos hacer un análisis riguroso del mismo:

1) En primer lugar, un análisis de las partidas y contenidos del pacto permite ver que no está destinado a la garantía de derechos, sino a la adaptación de las estructuras estatales y sociales a las nuevas necesidades del capital.

Intervención estatal no significa, necesariamente, centralidad estatal. A diferencia de lo que decía Adam Smith, el mercado no se regula ni funciona por sí solo. Para que la reproducción ampliada de capital se pueda dar y funcionar regularmente se ha requerido, históricamente, de todo un conjunto de condiciones político-jurídicas. Por ejemplo: para obtener plusvalor o excedente que reinvertir es necesario asegurar que exista una demanda suficiente para que la cantidad cada vez mayor de mercancías producidas se pueda vender; para reinvertir parte del excedente en mejorar los medios de producción es necesario que exista otro capitalista que haya decidido invertir en la fabricación de la maquinaria necesaria para el primero, teniendo conocimiento antes de producirla de que la va a vender; o, para conseguir más y mejor capacitada fuerza de trabajo que permita aumentar la producción es necesario que se hayan creado escuelas y universidades para la formación de los futuros trabajadores. En consecuencia, la reproducción ampliada no se puede dar en un contexto de mera espontaneidad, sino que necesita, para poder funcionar, de circunstancias económicas, pero también políticas que garanticen las condiciones necesarias para su reproducción. Esto es, la intervención del Estado.

Aún y su debilitamiento en la época neoliberal, los Estados no pierden su papel como complejo condensador de la reproducción del capital. Aunque los criterios de inversión sean desplazados a órganos internacionales, los Estados continúan conformando y garantizando la dinámica del capital. En medio de la quiebra económica de los Estados ocasionada por la crisis de 2007-2008, la aprobación de la reforma constitucional del art. 135 CE y la Ley Orgánica 2/2012, de 27 de abril, de Estabilidad Presupuestaria y Sostenibilidad Financiera, son estructuras jurídicopolíticas necesarias para que el capital financiero internacional pueda ver garantizada su reproducción mediante el saqueo de lo público. La pérdida de poder soberano de los Estados no implica la pérdida de su papel como estructura de intervención y 
organización jurídico-política del proceso de reproducción ampliada. Pero eso, ni significa centralidad estatal ni que el Estado se constituya como una estructura generadora de igualdad, sino todo lo contrario, subordinación del Estado a la centralidad del capital y su conformación como estructura generadora de desigualdad.

En la actualidad, los principales problemas con los que se encuentran los grandes capitales son: A) Una situación de fuerte crisis económica, en el marco de la crisis económica mundial provocada por la COVID-19, y B) la existencia de una estructura estatal y social disfuncional a las nuevas necesidades de desarrollo del capitalismo que el nuevo escenario ha creado.

Una revisión de los dos instrumentos jurídicos sobre los que la UE estructura el llamado plan de reconstrucción post-pandemia -el presupuesto de la UE llamado Marco Financiero Plurianual 2021-2027 (MFP) y el plan de fondos adicionales «Nueva Generación UE» (NGUE)- permite ver, claramente, que el objetivo de los mismos no es re-empoderar a los Estados como marco garantista de derechos para los ciudadanos, sino utilizarlos para llevar a cabo un conjunto de reformas estructurales que permitan adecuar la estructura estatal y social a las nuevas necesidades de reproducción del Capital en el nuevo escenario post-pandemia. Fijémonos, ¿de dónde sale el dinero y cuáles son las principales partidas del Plan NGUE destinadas a programas individuales para los Estados? Esto es importante para entender el objetivo que se esconde detrás del Plan.

El plan NGUE es un fondo adicional de dinero destinado a reforzar el presupuesto de la UE (MFP) 2021-2027 ante el advenimiento de la pandemia. En concreto, se trata de un fondo de 750.000 millones $€$ que la UE solicita en forma de crédito a los mercados de capitales. ¿A qué destinará la UE esta cantidad de dinero?

El borrador presentado por la Comisión Europea, en febrero de 2020, para iniciar la negociación entre Estados establecía que los montos del Plan (750 mil millones $€$ ) se distribuían de la siguiente manera: Instrumento para la Recuperación y la Resiliencia (560 mil millones $€$ ); ReactEU (50 mil millones $€$ ); Horizonte Europa (13,5 mil millones $€$ ); Inversiones InvestEU (30,3 mil millones $€$ ); Instrumento de apoyo a la Solvencia (26 mil millones $€$ ); Desarrollo rural (15 mil millones $€$ ); Fondo de Transición Justa para el clima (30 mil millones $€$ ); RescEU (2 mil millones $€$ ); Programa de salud (7,7 mil millones $€$ ); y, $\mathrm{NDICl}$ (15,5 mil millones $€$ ).

Sin embargo, el documento final aprobado tras la negociación de los Estados establece su distribución de la siguiente manera: Instrumento para la Recuperación y la Resiliencia (672,5 mil millones $€$ ); ReactEU (47,5 mil millones $€$ ); Horizonte Europa ( 5 mil millones $€$ ); Inversiones InvestEU (5,6 mil millones $€$ ); Desarrollo rural (7,5 mil millones $€$ ); Fondo de Transición Justa para el clima (10 mil millones $€$ ); y, RescEU $(1,9$ mil millones $€)$.

Así pues, la partida «Programa de salud» desaparece o el Instrumento de Solvencia propuesto por Bruselas para ayudar a empresas en problemas también se elimina. Otras partidas como la de InvesEU se mantienen. InvesUE es el nuevo nombre del antiguo Plan de Inversiones para Europa, conocido como Plan Juncker, entre cuyos objetivos está eliminar los obstáculos a la inversión mediante tres pilares, el tercero de los cuales es: «mejorar el entorno de las empresas eliminando los obstáculos (nacionales y europeos) a la inversión», léase más neoliberalismo y libre mercado. Pero la partida del fondo de reconstrucción que pasa a incrementar su dotación de manera más clara es el Instrumento para la Recuperación y la Resiliencia. ¿En qué consiste esta partida? 
Se trata de la partida dedicada a la transferencia de dinero hacia los Estados, una parte en forma de créditos y otra de subvenciones, para que lleven a cabo inversiones en sus territorios que tengan como prioridad, señala el NGUE: la transición ecológica de acuerdo con los criterios del Pacto Verde Europeo y la transición digital de acuerdo con la llamada Estrategia Digital Europea.

El Pacto Verde Europeo, según lo define la propia Comisión Europea, es «una nueva estrategia de crecimiento para la UE tendente a transformarla en una sociedad climáticamente neutra, equitativa y próspera, con una economía moderna, eficiente en el uso de los recursos y competitiva». A la vez, la Estrategia Digital Europea fija como objetivos: «Invertir en competencias digitales para todos los europeos; acelerar el despliegue de banda ancha ultrarrápida para los hogares, escuelas y hospitales de la UE; posibilitar que acceda a la financiación y se expanda una comunidad dinámica de empresas emergentes y pymes innovadoras y de rápido crecimiento; proponer una Ley de servicios digitales que refuerce la responsabilidad de las plataformas y aclare las normas aplicables a los servicios online; garantizar que en la economía digital las normas de la UE se adecuen a su propósito; garantizar que en Europa todas las empresas compitan en condiciones justas; mejorar el acceso a datos de alta calidad al tiempo que se garantiza la protección de los datos personales y sensibles; etc.».

Curioso ver que, en España, en 2016 la CEOE aprobó el documento Plan Digital 2020. La digitalización de la sociedad española ${ }^{1}$, fijando la digitalización como necesidad estratégica fundamental para llevar a cabo «una transformación cultural» que "genere nuevos modelos de negocio».

Viendo esto no parece haber duda alguna que el objetivo del Plan de reconstrucción NGUE no es, como decía, re-empoderar a los Estados como marco garantista de derechos a los ciudadanos, sino utilizarlos para llevar a cabo una transformación cultural y reformas estructurales que permitan adecuar la estructura social y estatal a las necesidades de reproducción del Capital en el nuevo capitalismo salvaje post-pandemia. ¡Primera manera curiosa de revertir la tendencia histórica neoliberal en favor del Capital y recuperar la centralidad estatal en favor de las personas, como parece afirmar que está sucediendo Sebastián Martín!

2) En segundo lugar, el Plan NGUE implica un desmontaje de la soberanía parlamentaria estatal. El acuerdo elimina cualquier resorte de pluralismo político y soberanía parlamentaria que pudiera quedar en el interior de los Estados. Para poder recibir las trasferencias del Instrumento para la Recuperación y la Resiliencia, los Estados deben elaborar planes nacionales en los que se expongan los programas e inversiones que van a realizar para el periodo 2021-2023. En el plazo de dos meses de la presentación, la Comisión Europea evaluará y aprobará los planes, previo dictamen del Consejo Económico y Financiero. «El desembolso de las subvenciones se realizará solo si se cumplen lo hitos y objetivos acordados establecidos en los planes de recuperación y resiliencia». Además «en el caso, excepcional, que uno o más Estados miembros consideran que existen serias desviaciones del cumplimiento satisfactorio de las metas y objetivos pertinentes, pueden solicitar que el Presidente del Consejo Europeo remita el asunto al próximo Consejo Europeo», suspendiéndose la transferencia económica.

Con ello se da una vuelta de tuerca más en la eliminación del sistema de representación propio del Estado democrático parlamentario, la representacióndelegación, donde a través de unas elecciones, la mayoría parlamentaria

1 http://contenidos.ceoe.es/CEOE/var/pool/pdf/publications docs-file-334-plan-digital-2020-ladigitalizacion-de-la-sociedad-espanola.pdf 
correspondiente determinaba las políticas públicas de acuerdo con la orientación ideológica mayoritaria en la población. Esto se sustituye por un modelo de representación-figuración que se personifica en órganos tecnocráticos neoliberales internacionales no electos, siendo ellos los que deciden cual debe ser las políticas públicas de inversión de los Estados. ¡Segunda curiosa manera de recuperar la centralidad del Estado que señala Martín!

3) $Y$, en tercer lugar, se trata de un plan que incrementa, aún más, la deuda de los Estados. Tras la negociación entre Estados, la partida del Instrumento para la Recuperación y la Resiliencia dedicada a subvenciones a los Estados se redujo hasta 312.500 millones $€$ y la de créditos aumentó hasta 360.000 millones $€$. La elevada partida reservada a créditos, superior a la de inversiones, incrementa la actual bola de deuda de los Estados. Más créditos significa más deuda y más deuda significa menos autonomía.

Pero es que, además, los instrumentos del MFP y el NGUE no son la única respuesta económica de la UE para hacer frente a la situación post-pandemia, ni siquiera la más importante. En paralelo a estos dos instrumentos señalados, la medida más importante, en términos macroeconómicos, que se ha anunciado desde Europa es el programa de compra de títulos de deuda pública del BCE, esto es, la concesión de créditos a los Estados por valor de 955.000 millones $€$. Medida a la que el Tribunal Constitucional alemán ha mostrado su rechazo por ser contraria a Derecho y que profundiza en un modelo que consistiría en apuntalar la recuperación inundando el mercado de deuda con miles de millones de euros. ¡Tercera curiosa manera de revertir la tendencia histórica neoliberal basada en la centralidad del capitalismo financiero y recuperar la centralidad estatal, como señala el profesor Martín, que no consiste en cancelar deuda sino en imponer más!

En resumen, parece que un análisis riguroso del plan de reconstrucción postpandemia de la UE nos pone ante los ojos una realidad que se empeña en confirmar el escenario de profundización del capitalismo financiero internacional y de transformación cultural y estructural de nuestras sociedades en favor del proyecto del Capital y no del proyecto garantista estatal en favor de los derechos de las mayorías sociales. Lo cual hace del todo incomprensible que Sebastián Martín pueda afirmar que «la respuesta institucional a la misma (la pandemia) en Europa ha vuelto a colocar sobre el tapete una centralidad estatal».

\section{Respuesta a Ricardo Cueva}

Leído el comentario del profesor Cueva Fernández (2020), solo puedo decir que se trata de una mezcla, por un lado, de insinuaciones sin argumentar que no permiten ningún tipo de respuesta y, por otro lado, de monoteísmo liberal, posición teórica desde la que resulta imposible comprender muchos de los complejos planteamientos del libro. Explico cada uno de estos dos aspectos.

\subsection{Las insinuaciones sin argumentar}

La verdad es que resulta difícil poder articular algún tipo de respuesta al comentario de Ricardo Cueva. El objetivo de esta sección Book Forum entiendo que consiste en que un discussant manifieste, de manera clara, cuales son aquellas partes o tesis del libro elegido por la revista con las que coincide y cuáles no. Y, en las que no coincide, argumentar cuales son los motivos de sus objeciones y su posición al respecto, de manera que ello permita abrir, mediante la réplica, un diálogo teórico rico con el autor del libro. 
Sin embargo, por mucho que leo el comentario del profesor Cueva Fernández no logro encontrar nada de ello. Lo que se haya en su comentario es, mayoritariamente, un texto hecho de insinuaciones e interrogaciones sin argumentar sobre partes del libro en las que sobreentiendo que no está de acuerdo, pero sin que especifique ni los motivos de por qué no las comparte ni, tampoco, cuál es la posición que defiende. Difícilmente se puede entrar a dialogar con alguien si no da a conocer ninguno de estos dos aspectos.

\section{Pongo varios ejemplos:}

1. Podemos decir, de manera muy general, que en el primer capítulo del libro se expone la idea de que la noción contractualista de soberanía, desarrollada a lo largo de los s. XVII y XVIII por los iusnaturalistas, permitió operar una reorganización de las relaciones materiales e ideológicas que fijó las bases para el tránsito del modo feudal al modo capitalista de producción, así como para la creación de la ideología de la soberanía como imaginario de legitimación del Estado liberal moderno. Sobre ello, el profesor Cueva escribe: "(Noguera) derriba de un plumazo todas las teorías contractualistas típicas que llevan décadas orbitando alrededor de la teoría de la justicia. (...) El enemigo a batir es la noción contractualista, de modo que la distinción entre contrato y pacto, tan útil a otros, no parece interesarle a Noguera. (...) Hasta aquí hay una declaración de lo que se propone y por qué caminos quiere discurrir: los de esquivar, a toda costa, las teorías quizás más en boga hoy acerca de la justicia». No dice más.

Por el tono que utiliza -«derriba de un plumazo», «la distinción entre contrato y pacto, tan útil a otros, parece no interesarle a Noguera», "esquivar a toda costa», etc.- deduzco que Ricardo Cueva no está conforme con la argumentación desarrollada en el libro. Pero digo deduzco porque, en ningún momento, plantea los motivos por los cuales no está de acuerdo (si es que es así) ni cuál es su posición. ¿Será porque es contractualista?, ¿o no lo es? Pues no lo sé. ¿Por qué dice que pretendo esquivar a toda costa las teorías más en boga hoy acerca de la justicia y cuáles son, para él, estas teorías? Tampoco lo sé.

¿A qué se refiere cuando dice que no me interesa la distinción tan útil entre contrato y pacto? Tampoco lo explica, cosa que sería útil de verdad, especialmente, teniendo en cuenta que al formular la teoría que sirve de fundamento al Estado y al Derecho liberal moderno, los autores iusnaturalistas del s. XVII y XVIII nunca distinguieron entre contrato y pacto. Si bien muchos de los iusnaturalistas señalaron que para la conformación de las formas aristocrática y monárquica de Estado son necesarias dos convenciones sucesivas: el pactum societatis, en la que un grupo de individuos deciden de común acuerdo vivir en sociedad (transformando una «multitudo» en un «populus»), y el pactum subiectionis, en la que una vez reunidos de tal manera se someten a un poder común (transformando un «populus» en «civitas»). Ello no resulta necesario, dicen, en la forma democrática de Estado base de la forma política liberal moderna surgida de las revoluciones burguesas. El hecho de que para Hobbes la mejor forma de gobierno fuera la monárquica, que sí requería de las dos convenciones, no impide que una de las innovaciones que él mismo introduce al teorizar, en el De Cive (2000), sobre la conformación del Estado democrático fuera la de eliminar uno de los dos pactos. El pactum unionis, ideado por Hobbes para acceder a la forma democrática de gobierno, es al mismo tiempo un pacto de asociación y de sujeción. Lo mismo señala Pufendorf en De iure naturae et Gentium, donde observa que, a diferencia de la forma aristocrática y monárquica, en la forma de gobierno democrático «la estructura del segundo pacto no es muy clara ni necesaria porque se trata de las mismas personas que bajo dos aspectos diferentes mandan y obedecen» (1943: 165-166). Esta reducción de los dos pactos a uno se da 
también en El contrato social de Rousseau para quien en «cada uno, uniéndose a todos, no obedece sino a sí mismo y permanece tan libre como antes» (1970: 730), no puede haber un segundo pacto si la soberanía no puede ser alienada a ningún poder superior. El mismo Rousseau dice «no hay más que un contrato en el Estado, el de asociación y éste por sí solo excluye cualquier otro» (1970: 805). Asimismo, aunque de forma menos explícita, también lo planteó Spinoza en el Tractatus theologico-politicus (1986) para quien, al igual que Rousseau, la única forma de gobierno que le interesa es la democrática.

Por tanto, si el recensor quiere reprocharme que al hablar de los fundamentos teóricos de la conformación del Estado moderno liberal capitalista desarrollados durante los s. XVII y XVIII no hablo de una supuesta diferencia entre contrato y pacto o entre dos pactos de la que los autores iusnaturalistas, a los que se refiere el capítulo del libro, no solo no hablaron nunca sino que, además, la eliminaron, lo mínimo que debería hacer es desarrollar a qué se refiere con ello.

2. El profesor Cueva va desglosando el contenido del libro por orden de capítulos, de inicio a fin. Ventilado el primer capítulo, entra en el segundo, y señala: «Tras explicar la aparición del mercado en la teoría política y social del siglo XVIII (Mandeville, Smith), y acudiendo al esquema habitual que utilizaran los ilustrados escoceses y luego Hegel para separar la sociedad civil del Estado, Noguera acaba sosteniendo que "tanto la socialdemocracia como el comunismo oficial pasaron a ser sinónimo de la defensa y promoción del intervencionismo de Estado como mecanismo desmercantilizador enfrentado a la sociedad-mercado" (p. 39). El autor, claro es, rechaza esta dicotomía (p. 41), pero de momento no indica alternativa alguna».

Recriminar al autor de un libro de 5 capítulos y 162 páginas que en el capítulo 2, páginas 39-41, todavía no ofrece ninguna alternativa, resulta poco serio. Esta es una valoración que, en su caso, debería realizarse tras la lectura completa de la obra, especialmente si tenemos en cuenta que si algo hace el libro, independientemente de si se está de acuerdo con ello o no, es replantear radicalmente el concepto tradicional de Constitución y de constitucionalismo imperante en la doctrina.

3. En este mismo capítulo segundo, el libro hace referencia al debate de la Steurungsdiskussion, acerca de las transformaciones del Estado planteado, en la década del 2000, por la doctrina jurídico-pública alemana (Schoch, 2008; Franzius, 2003; Vesting, 2000), en el marco del cual se dice que durante el Estado social del siglo XX el Estado asumía, en materia de derechos, servicios y prestaciones, tres responsabilidades: la responsabilidad de garantía, también calificada de directiva o infraestructural; la responsabilidad de cumplimiento o ejecución, y la responsabilidad de financiación.

Sobre ello, Ricardo Cueva afirma: «Sin entrar ahora en si esta división (de nuevo tripartita) es correcta (parece que la segunda responsabilidad es sospechosamente parecida a la primera)». Más de lo mismo. El tono utilizado («sospechosamente») demuestra no solo que, a pesar de negarlo, sí está entrando, sino que además tampoco está conforme con la división. "Sospechosamente», ¿por qué? De nuevo, ni una sola palabra dedicada a explicar la razón de este calificativo.

4. Más adelante, se refiere a mi planteamiento acerca de la complejización del espacio sociopolítico o campo de lucha de los derechos. Sobre este, se sobreentiende que tampoco está de acuerdo. En primer lugar, porque afirma que «una perspectiva más apegada a la Historia serviría para descubrir que la fragmentación social que hoy nos parece tan grande en realidad ya existía en tiempos de la Revolución industrial», sobre esto volveré más adelante; y, en segundo lugar, por la afirmación con la que 
cierra el asunto: «Cierta atracción por enfoques posmodernos implica este tipo de aproximación, obviamente».

Ricardo Cueva usa el recurso de la acusación de posmoderno como algo que ya, de por sí, debe interpretarse como desacreditador, «obviamente», sin necesidad de tener que explicar cuáles son, para él, estos enfoques posmodernos ni por qué serían desacreditadores de una tesis. Como no argumenta los motivos se me hace difícil contrarrestarlos. Pero, en cualquier caso, lo que sí puedo decir es que lo que él considera como una contaminación reprochable y desacreditadora, para mí es algo bueno. Reprochar y ver como negativo que alguien complemente el marxismo, que es el fundamento teórico-metodológico sobre el que se construye la argumentación del libro, con lo que él llama «enfoques posmodernos» resulta, y más aún si no lo justifica, incomprensible.

El marxismo se construyó como proyecto político a partir de la combinación, en lo práctico, del despliegue histórico de las características del capitalismo en occidente de los siglos XIX y XX. Y, en lo teórico, por la influencia de la economía política, que aporta la explicación de la organización de los procesos de producción, de intercambio y de generación de riqueza; la filosofía hegeliana, que introduce una concepción de la historia como autodesarrollo, a través de diferentes momentos del desarrollo de la conciencia, mediada por el trabajo que transforma la naturaleza, y el socialismo utópico, que aporta la crítica a la desigualdad y la sociedad capitalista, bosquejando un proyecto de vida social igualitaria. Este se construyó, por tanto, como teoría unitemporal, es decir, usando categorías y conceptos propios de una forma de capitalismo histórico-concreta. Unicultural, es decir, sobre la tradición teórica moderna occidental. Y, unigénero, es decir, ideado por hombres blancos.

Ello hace que sea una teoría incompleta y que presenta límites o déficits temporales, pues en tanto piensa la realidad social como realidad histórica, el carácter cambiante de lo social lleva a su incompletud permanente. Así como límites o déficits culturales, pues piensa la realidad social desde una determinada forma de sociedad y cultura que no es la única. $Y$ en un mundo donde existe una diversidad de sociedades y culturas, la teoría que se piensa desde una sola de ellas es incompleta y limitada. También presenta límites y déficits de género, en tanto que, tradicionalmente, ha pensado la historia como historia hecha por los hombres.

La transcrítica es un concepto desarrollado por el filósofo japonés Kojin Karatani (2005) y retomado después por Luis Tapia (2017), que consiste en una forma de autocrítica de una teoría y solución de sus límites a través de procesos de diálogo con otras teorías. Y aquí podríamos incluir el diálogo intrasocietales, esto es, con otras teorías histórico-temporales distintas del mismo tipo de sociedad y cultura, por ejemplo, integrando el marxismo con el postestructuralismo o lo que Ricardo Cueva llama «enfoques posmodernos». El diálogo intersocietal, referido al diálogo e integración en el marxismo de teorías provenientes de otros tipos de sociedad y cultura, como la teoría o conocimientos indígenas (que imagino también deben incluirse en sus «enfoques posmodernos»). Y añadiríamos el diálogo intergénero, la integración en el marxismo de los feminismos. Se trata de realizar un trabajo de integración teórica, desarrollando los elementos deficitarios del marxismo con elementos que han sido desarrollados por otras teorías.

Solo abandonando la ortodoxia purista marxista no contaminada para nadie ni nada, con un marxismo transcrítico que conciba «los enfoques posmodernos» no como una amenaza sino como una teoría con quien dialogar para suplir déficits y límites, se puede entender y pensar la realidad de hoy. Ver la integración entre 
marxismo y teorías de otros tiempos como una contaminación a criticar resulta de un dogmatismo importante.

5. Ubicado en el capítulo cinco del libro, Cueva Fernández identifica mi noción de lucha de sujeto, objeto y práctica plural con el sujeto de Negri: «Noguera emplea, en cambio, el término "diversidad" y lo identifica, lisa y llanamente, con el de la multitud negriana». Pero, a la vez, en el párrafo inmediatamente posterior, lo identifica también con el sujeto de Laclau: «si sustituimos derechos por reclamos, a la manera de Laclau (La Razón Populista), la operación nos podría resultar familiar». En esta ocasión, las insinuaciones no solo carecen de mayor desarrollo argumental, sino que además se contradicen. ¿En qué quedamos? Debo interpretar que lo identifico con Hardt y Negri (el primero ni siquiera existe para Cueva a pesar de que la obra a la que se refiere es en coautoría) o con Laclau? Porque los planteamientos de ambos acerca del sujeto colectivo son opuestos.

Los dos parten de reconocer que en nuestras sociedades existe una pluralidad de movimientos sociales con reivindicaciones diferenciales (movimientos feministas, antirracistas, de la tercera edad, LGTBIQ, indígenas, de la clase obrera industrial, de los campesinos sin tierra, etc. Sin embargo, el objetivo de E. Laclau es pensar cómo puede pasarse de las reivindicaciones particulares de cada uno de ellos a una reivindicación hegemónica que pueda unificarlos a todos. Su objetivo es lograr pasar, a través del unívoco equivalencial, de las particularidades diferenciales a una reivindicación hegemónica universal de igualdad-identidad que los englobe y unifique. La propuesta de M. Hardt y A. Negri va, por el contrario, en otro sentido. Estos piensan que a través del diálogo, la información mutua, la praxis militante compartida y la traducción de sus propuestas, cada uno de los movimientos puede ir incorporando las reivindicaciones de los otros movimientos en la propia, lográndose el entendimiento y conformación de un bloque social entre ellos, pero sin que ello signifique nunca una universalidad englobante. Precisamente por ello, Hardt y Negri (2004, p. 108) oponen multitud, como ellos la definen, a la noción de pueblo como concepto de igualdadidentidad que nos unifica a todos por encima de nuestras particularidades como miembros de un nosotros en alteridad con un ellos, propia de Laclau y que rechazan.

Hubiera estado bien que el profesor Cueva clarificase con cuál de los dos identifica mi noción de lucha de sujeto, objeto y práctica plural. Con los dos a la vez no puede ser. De ser así, me hubiera sido más fácil responderle.

6. Otro de los elementos que sorprende es la crítica que formula a mi texto a partir de una identificación entre socialismo científico y estatismo. Cueva dice: «Hasta aquí, el autor se pronuncia de una manera crítica que nos recuerda indudablemente a numerosos otros en búsqueda de modelos sociales alternativos. En realidad, mucho más a los socialistas utópicos o a los cooperativistas que a los pensadores del socialismo científico. Esto lo muestra a las claras también su asunción de un "pluralismo económico" (p. 146) incompatible con propuestas de planificación o intervención fuerte».

Según Cueva, el hecho de que no apueste por un modelo basado única y exclusivamente por la planificación centralizada estatal «muestra» mi identificación más a los socialistas utópicos que a los socialistas científicos. Como si la diferencia entre ellos hubiera sido alguna vez que el socialismo utópico fuera comunalista y el socialismo científico (Marx y Engels) estatista. Esta nunca fue la diferencia entre ambos. Marx y Engels nunca fueron estatistas. Eran tan comunalistas y antiestatistas como los socialistas utópicos. No existe en Marx una teoría explícita del Estado y la planificación, no solo porque Marx nunca la desarrolló, sino también por la imposibilidad teórica de que exista. 
Para Marx, la planificación o el intervencionismo estatal solo podía ser capitalista, nunca anticapitalista. Muchas veces se comete el error de pensar que la microeconomía y el Derecho civil en tanto estudian y regulan la circulación de mercancías son la ciencia y la técnica propia del capitalismo, mientras que la macroeconomía y el Derecho económico en tanto estudian y regulan la intervención estatal sobre la economía son la ciencia y la técnica contraria al capitalismo. Esto es absolutamente falso. La microeconomía y el derecho civil o intercambio de mercancías son el fenómeno primario pero no esencial del capitalismo. El mercado o intercambio no necesariamente deben usarse para acumular cada vez más beneficios, sino que pueden usarse con otros objetivos. En cambio, la macroeconomía y el Derecho económico sí que constituyen el fenómeno esencial del capitalismo. Este es el que se ocupa de organizar y garantizar el proceso general de expansión o revalorización constante del capital, que solo es posible mediante la extracción cada vez mayor de plusvalía sobre la fuerza de trabajo o la naturaleza (Correa, 2013, p. 254).

Esto no quiere decir que la intervención estatal y la macroeconomía no deban ser utilizadas por la izquierda política. El ámbito de la macroeconomía o del derecho económico siempre expresa una forma de organizar la reproducción ampliada de capital a partir de la generación de plusvalía y por eso no se puede pensar en él como un ordenamiento que tiende a superar el capitalismo como forma de producción social. Sin embargo, sí que en su interior existen ciertos márgenes de maniobra. En función de si quien determina la planificación económica, el contenido del derecho económico es un sujeto de izquierda o de derecha, el plusvalor que surge de la reproducción expansiva del Capital se puede destinar a servicios y a la protección social de los menos favorecidos o a engordar la riqueza de unos pocos incrementando las desigualdades sociales, lo que no es poco. Pero eso hace referencia a las formas de redistribución de la riqueza dentro del capitalismo, no a la superación del capitalismo que es el objetivo político central del socialismo científico.

Por tanto, como digo, lo que los socialistas científicos critican del socialismo utópico no es el anti-estatismno ni el objetivo del comunismo, que era compartido Marx y Engels eran profundamente anti-estatistas-, sino la manera en que pretendían llegar al comunismo.

Saint-Simon, Owen, Fourier, Cabet, etc. basaban su crítica al capitalismo en los valores morales propios de este (competitividad, egoísmo, etc.) y el paso al comunismo se conseguía creando sociedades ideales paralelas en cuyo interior estos valores se sustituyeran por otros de solidaridad y armonía, imponiéndose ipso facto una sociedad perfecta de igualdad absoluta e ignorando, de esta manera, el papel de la lucha de clases y soslayando los dilatados procesos históricos que demandan la transformación o tránsito del capitalismo al comunismo. Frente a este modelo, Marx y Engels sostenían que la crítica al capitalismo no debía ser una crítica moralista, sino de su base material, una crítica de la economía política. El paso al comunismo solo podía ser fruto de un proceso de lucha de clases y conflicto destinado a la subversión de las relaciones de producción en el curso de la cual, y de manera dialéctica, la transformación de la realidad material operaba un cambio en la conciencia de los trabajadores y a la inversa, de manera que las condiciones de la actividad son producidas por la misma actividad.

La clase obrera no esperaba de la Comuna ningún milagro. Los obreros no tienen ninguna utopía lista para implantarla «par decret du peuple». Saben que para conseguir su propia emancipación, y con ella esa forma superior de vida hacia la que tiende irresistiblemente la sociedad actual por su propio desarrollo económico, tendrán que pasar por largas luchas, por toda una clase de procesos históricos que transformarán las circunstancias y los hombres (Marx y Engels, 1955, p. 547). 
Esta es la crítica a través de la cual el socialismo utópico devino en socialismo científico. En ningún caso lo fue que el primero fuera comunitarista y el segundo estatista y quisiera la planificación centralizada estatal.

La ideología de la soberanía desarrolla el espacio del común como un campo de lucha atravesado por el conflicto entre el procomún extractivo y cooperativo, que además se solapa con otros ejes o campos de lucha: el estatal (público-privado) y el internacional (entorno de igualdad-desigualdad). Es a través de la coexistencia y complementariedad de la lucha de clases en los tres ejes que se logra transitar en el largo proceso de la emancipación. Con ello, parece no haber ninguna duda que el libro no plantea el proceso emancipador como la implantación de una sociedad ideal que pase a crear inmediatamente, sin lucha ni transiciones, un reino ideal. De manera que no tiene ningún sentido identificar la propuesta del libro con el socialismo utópico. A no ser, claro, que te inventes que lo que te identifica con el socialismo utópico o el científico es si apuestas por un modelo de planificación centralizada estatal como única forma de gestión o no.

Podría ahondar en más ejemplos, pero resultan suficientes para demostrar que nos hallamos ante una crítica hilvanada de insinuaciones sin argumentar y con la consiguiente falta de rigor que impide, lamentablemente, entablar un diálogo rico entre posiciones discordantes acerca de los diferentes aspectos del libro en cuestión.

\subsection{El monoteísmo liberal}

Entre el conjunto de insinuaciones a las que nos hemos referido puede verse, además, como el profesor Cueva enfoca la lectura del libro desde una posición de monoteísmo liberal, cosa que lo lleva a considerar incomprensibles cuestiones que vistas desde una perspectiva politeísta no liberal, desde la que parte el libro, no lo son.

Denomino monoteísmo liberal (que también puede ser de izquierdas) a aquella posición científica que asume como universales e incuestionables ciertas premisas y lógicas propias de la modernidad racional, y por tanto liberales, negando o no concibiendo que pueda existir nada más allá de ello. Se trataría de una especie de anteojeras que impiden ver más allá de ciertos esquemas, percibiendo todo lo que supera los mismos como irracional y por tanto, por definición, incomprensible.

Esta posición puede identificarse claramente en la manera en que Ricardo Cueva aborda algunas cuestiones. Pongo algunos ejemplos:

- Uno es cuando afirma que al hablar de luchas de «de sujeto, objeto y prácticas plurales [Noguera] parece añadir confusión a cualquier receta, ya que ni se considera a un sujeto individual moral indeterminado (universal, diríamos), ni tampoco a otro colectivo agrupado bajo un programa de acción política. ¿De quién habla exactamente Noguera? ¿Quiénes son las "clases populares" a las que aquí se refiere?». Con esta afirmación Ricardo Cueva parece sorprenderse y rechazar que alguien pueda afirmar que más allá de la contradicción binaria entre el individualismo metafísico liberal y el colectivismo sustantivo del marxismo ortodoxo puedan existir otras subjetividades. Sin duda, desde el monoteísmo liberal no, pero desde un politeísmo no liberal claro que pueden existir. 
- Otro es cuando al referirse a la noción de reformismo revolucionario dice: «Pero aquí ya el ataque no es frontal. Es más, la supuesta radicalidad de las propuestas anteriores choca con el intento de construcción constitucional que ahora desfila ante nosotros. Así, el alterconstitucionalismo sería, y sin temor al oxímoron, (...) una estrategia de reformismo revolucionario». Con esta afirmación Ricardo Cueva se sorprende y rechaza que alguien pueda dejar atrás y superar la contradicción binaria, propia del s. XX, entre revolución y reforma, y conciliar ambos conceptos para describir una nueva estrategia de lucha. Sin duda, desde el monoteísmo liberal es incomprensible y es un oxímoron, pero no desde un politeísmo no liberal.

Podríamos poner más ejemplos. Otro sería cuando se pregunta: «[Noguera] [p]lantea un nuevo sistema de relaciones sociales, políticas, económicas y culturales anticapitalista, aunque construido desde el constitucionalismo. Pero, ¿acaso no había dicho ya Noguera que la soberanía es una ideología? ¿Hay un constitucionalismo que no la presuponga?» Desde el monoteísmo liberal en que la soberanía solo puede entenderse como terreno de soberanía singular y centralizada no lo hay. Pero desde el politeísmo no liberal donde la Constitución puede pensarse como terreno de soberanías plurales sí la hay. Sin embargo, y por una cuestión de no alargar en exceso esta respuesta, me detendré solo en los dos primeros ejemplos de monoteísmo liberal que acabo de exponer.

\subsubsection{El espacio sociopolítico y la lucha de sujeto, objeto y práctica}

Respecto a la cuestión del sujeto, una vez ha explicado la complejización del campo de lucha de los derechos en tres campos o ejes superpuestos, el libro plantea la necesidad de pasar de una lucha de sujeto, objeto y práctica singular a una de sujeto, objeto y práctica plural. Esto es, co-crear formas organizativas de lo colectivo y prácticas de conflicto de distinta naturaleza que operen como estructuras paralelas, plurales e interconectas de conflicto en los diferentes ejes de disputa de derechos con formas de explotación también diversas (el eje estatal público-privado, el eje procomún extractivo-cooperativo y el eje entorno internacional de desigualdadigualdad).

Cueva parece negar tanto la complejización del campo de lucha de los derechos que se formula en el libro como la posibilidad de que pueda existir esta lucha de sujeto, objeto y práctica plural.

Para el profesor Cueva esta complejización de la realidad sociopolítica sería una descripción «no apegada a la historia», una fragmentación exagerada de lo social ya que, según afirma, la sociedad de hoy «en realidad ya existía en tiempos de la Revolución industrial». "Entonces, -dice- numerosas familias al completo tejían para propietarios de la industria en sus propias casas. La "precarización" era un fenómeno constante que recorría un mundo repleto de desposeídos de sus tierras, así como braceros, marineros y campesinos arrendatarios». Resulta así afirmar que entre la estructura social de la sociedad de la revolución industrial y la sociedad actual con riders de Deliveroo, conductores de Uber, Airbnb copando el parque habitacional de nuestras ciudades, millones de personas teletrabajando en red desde casa o endeudadas con los bancos y con una economía financiarizada donde los procesos de acumulación ya no se dan produciendo mercancías sino mediante la especulación en el mercado bursátil, en realidad, no habría mucha diferencia.

Si partimos de la idea, como hemos explicado en la primera parte de este comentario, que el capitalismo no es un modo de producción estático, sino dinámico, que se redefine históricamente cambiando, a raíz de sus crisis, los modos de 
organizar la producción y el consumo para generar nuevas fases de acumulación, difícilmente es aceptable la afirmación de que las formas de lo social y la estructura social de hoy ya existía hace un siglo atrás. El funcionamiento de cada una de las fases de acumulación (fordista, postfordista, etc.) requiere de condiciones políticojurídicas y de formas de lo social o estructuras sociales (modos de regulación) distintas. El tipo de clases, grupos, individuos, trabajador-tipo que existen en una sociedad histórico-concreta y las interacciones entre ellos no se dan de modo ocasional o aleatorio, sino que son el resultado de las necesidades históricas de un determinado modo de organizar la producción y el consumo en esa fase determinada del capitalismo. No, únicamente, son los sujetos los que crean las fases del capitalismo, sino que son estas también las que crean los sujetos y formas sociales funcionales a ellas. La reproducción del capitalismo se estructura a través de formas y estructuras sociales necesarias y específicas, que constituyen el núcleo de su propia reproducción. Entre el modelo de capitalismo de cada época y la estructura social del momento existe siempre un acoplamiento funcional. Así, mientras que el capitalismo industrial fordista, donde el proceso de acumulación se desarrollaba a través de la retroalimentación entre la producción en serie y el consumo de masas, requería para poder funcionar de empresarios schumpeterianos y trabajadores con derechos sociales y capacidad de consumo, el capitalismo transnacional especulativofinanciero digitalizado actual necesita de otro tipo de estructura social con sujetos, grupos e individuos distintos. Así pues, no parece muy aceptable afirmar que la estructura social no evoluciona ni se transforma en paralelo a como lo hace el capitalismo, que hoy ya no tiene nada de industrial fordista.

Pero además, la imposibilidad de Cueva Fernández por entender la transformación de la estructura social actual con respecto a la propia de la revolución industrial queda confirmando cuando afirma que al hablar de luchas de «de sujeto, objeto y prácticas plurales [Noguera] parece añadir confusión a cualquier receta, ya que ni se considera a un sujeto individual moral indeterminado (universal, diríamos), ni tampoco a otro colectivo agrupado bajo un programa de acción política. ¿De quién habla exactamente Noguera? ¿Quiénes son las "clases populares" a las que aquí se refiere?».

Como señalaba antes, con esta afirmación no solo parece estar reprochándome no definir, suficientemente, la subjetividad colectiva a la que me refiero, olvidando que en 2017 publiqué un libro entero dedicado exclusivamente a ello (El sujeto constituyente. Entre lo viejo y lo nuevo. Ed. Trotta), sino que, además, anclado en el monoteísmo liberal, le parece sorprendente que alguien pueda afirmar que existen sujetos no incluidos en lo que para él serían las dos únicas formas de sujeto posibles: "UN sujeto individual» o "UN sujeto colectivo agrupado bajo un programa de acción política». Según él, la construcción del sujeto solo puede expresarse como construcción liberal de un sujeto único individual alrededor de un cuerpo reconstruido en su unicidad, que tiene valor como realidad aislada e individual. O como construcción de un sujeto único colectivo (Trabajo) como unidad de intereses "agrupados bajo un programa de acción política» que se construye en alteridad contra otro sujeto (Capital). De manera que cuando alguien hace entrar en juego sujetos que no pertenecen a ninguna de esas dos categorías de sujeto único y universal lo acusa de «añadir confusión» «de manera poco apegada a la historia».

Se trata, ni más ni menos (no sé si de manera voluntaria o involuntaria porque tampoco lo manifiesta), de una reproducción del viejo esquema monoteísta que sigue pensando la lucha por la consecución de derechos y dignidad (objetivo que al inicio de su comentario Ricardo Cueva afirma compartir conmigo) desde un único sujeto universal, una única contradicción, una única causa de explotación, una única estrategia y un único programa de acción. De esta manera, el profesor Cueva continua 
anclado en la concepción trabajocentrista de la clase, propia de la revolución industrial, en la que el Trabajo se conforma como único sujeto histórico de lucha, negando que estamos experimentando en nuestras sociedades una pluralización de los sujetos e identidades de lucha, pasando de una sociedad donde la clase emancipadora ya no es una singular, sino que es múltiple y plural.

Podemos definir la clase social, en su dimensión «en síl, como la posición que las personas ocupan en la división o escalera social de recursos, facultades, oportunidades y privilegios. Y, en su dimensión «para sí», como la consciencia de tal posición y de sus causantes, esto es, de sus enemigos. Durante toda la época del capitalismo industrial, para el marxismo, la posición-conciencia en tal escalera venía dada solo por la posición que uno ocupaba respecto la propiedad de los medios de producción, con lo que la lucha de clases se daba entre trabajadores que lo único que tenían era su fuerza de trabajo y empresarios propietarios de las máquinas. De esta manera, se procedía a analizar la sociedad como un espacio ordenado de relación antagónica entre dos clases o grandes unidades de análisis prefijadas, fijas, estáticas y con bordes definidos: el Capital y el Trabajo. Todo conflicto se enmarcaba en el interior de esta división. Este es el esquema con el que pretende romper el libro cuando se refiere a las sociedades de hoy y es el que parece sorprender a Cueva Fernández.

Es cierto que cuando dice que en la sociedad de la revolución industrial similar, según él, a la de hoy- ya existían distintos tipos de trabajo («numerosas familias al completo tejían para propietarios de la industria en sus propias casas. La "precarización" era un fenómeno constante que recorría un mundo repleto de desposeídos de sus tierras, así como braceros, marineros y campesinos arrendatarios») está complejizando la noción de clase reducida al proletariado urbano industrial, pero viendo la crítica que lanza en su texto esta complejización se produce, en él, como falsa complejización, no como complejización real.

En él, se sobrentiende que la ampliación de la noción de clase se produce por vía de lo que podemos llamar la «inclusión del contrario». ¿Qué quiere decir esto? Pues que se complejiza el análisis pero no se supera del todo la concepción monista de un único conflicto de clase capital-trabajo. Al citar las familias que trabajan en casa, marineros, etc., supera la idea de clase homogénea basada en la centralidad del proletariado industrial urbano. Se acepta que el sujeto Trabajo nunca ha sido un sujeto homogéneo y se incluye en el interior las diversas formas de explotación y de trabajo productivo y reproductivo, pero no se supera la lectura trabajocentrista de todo conflicto. Se complejiza la clase, pero desde el principio de «inclusión del contrario». Es decir, se «abre la mente» y se entiende que si los trabajadores, que son el sujeto principal de la revolución, tienen derechos, los otros colectivos (mujeres, inmigrantes, gays y lesbianas, etc.) también deben tenerlos y por eso son aceptados como parte del «nosotros» clase, que ahora ya no es algo homogéneo sino diverso. Pero el punto de referencia desde la que se construye este nosotros inclusivo continua siendo la idea trabajocentrista de clase, por eso la inclusión de estas otras «identidades» se da en régimen de subordinación al que consideran el conflicto de clase único, el del trabajo contra el capital con un programa de acción política único, cuya resolución implicará a la vez, a su entender, la resolución de las todas las contradicciones en los demás ejes. De ahí que hable de una falsa complejización.

La complejización del sujeto histórico que plantea el libro va mucho más allá y es lo que parece sorprender al comentarista. Al trazarse un escenario en el que tienen presencia simultánea en el mismo presente social y político diversos ejes o campos de lucha cruzados (internacional, Estado y procomún) con formas de autoridad, legitimidad, economía y juridicidad diferentes en cada uno de ellos, el libro pone de 
manifiesto que vivimos en una sociedad en la que el acceso de las personas a los derechos no depende, única y exclusivamente (como si alguna vez lo hubiera hecho), de la posición que ocupan respecto los medios de producción, sino respecto a los múltiples ejes o campos de lucha entrecruzados: el del Estado (público-privado), el de la mundialización (entorno de igualdad-desiguadad) y el del procomún (cooperativo-extractivo), entre muchos otros. La posición de cada individuo en cada campo de lucha o eje se cruza para determinar posiciones privilegiadas 0 desfavorecidas distintas dentro del proceso de opresión y explotación. La ubicación objetiva del individuo dentro de la estructura social está determinada por la totalidad de estas complejidades, no solo por la posición que ocupa respecto los medios de producción o por si hay mayor sector público estatal o privado. ¿O acaso ser ciudadano de un país vendedor de deuda pública como Alemania o de uno comprador como Grecia, independientemente de si eres trabajador o empresario, no te otorga posiciones distintas en el proceso de opresión y explotación? ¿O tener un piso en propiedad o tener que alquilar una habitación de tu casa por Airbnb a turistas para poder pagar el alquiler o la hipoteca del mismo, independientemente de si eres trabajador de la Seat o empresario (porque hay trabajadores de la Seat que han heredado una vivienda en propiedad y autónomos hipotecados) no te otorga posiciones distintas en el proceso de opresión y explotación?

En este contexto sociopolítico de campos de lucha cruzados, y teniendo en cuenta que la vida de las personas es limitada en el tiempo y no pueden dedicarse a luchar por todas las causas en todos los ejes de explotación u opresión, hay personas que dedican sus horas disponibles a militar contra la deudocracia, otras que lo hacen por la regulación de los alquileres, otras por el antiracismo, otras por el feminismo, otras por sus condiciones laborales, etc. $Y$ ello crea múltiples sujetos, objetos y prácticas de lucha plurales en los distintos ejes que coexisten en un mismo presente sociopolítico.

En resumen, hablar de una lucha de sujeto, objeto y practicas plurales no es, como afirma Ricardo Cueva, algo que «añade confusión» y crea fragmentaciones que no se adecuan a la realidad, sino que es la realidad misma. Aunque ello solo se puede comprender desde un politeísmo no liberal capaz de superar la limitación de que solo pueden existir dos únicos tipos de sujetos universales, nunca desde el monoteísmo liberal.

Y ello tampoco implica, como también dice Cueva Fernández, una fragmentación de lo social en la que no puede existir sistematicidad ni unidad alguna. El aquí llamado monoteísmo liberal cree que lo contrario de la sistematicidad y la unidad es la diversidad. No es cierto. Lo contrario de la diversidad es la homogeneidad, y lo contrario de la unidad es la desunión o dispersión. Puede haber sistematicidad y acción unitaria sin sujeto único y universal.

\subsubsection{Revolución vs. reforma}

Como desarrolla el libro, vivimos en una sociedad compleja, donde se superponen en un mismo presente instituciones propias de la mundialización, la estatalidad y la autoorganización ciudadana y donde, a la vez, coexisten múltiples sujetos colectivos. Ello significa dos cosas.

En primer lugar, que el poder se ha complejizado. ¿Qué significa esto? El poder no existe en abstracto, el poder existe a través de aquellas instituciones que organizan las mediaciones de su ejercicio. Si antes eran, principalmente, el Estado y aquellas otras que conformaban el Estado ampliado (escuelas, medios de comunicación, asociaciones, etc.), la superposición a la realidad estatal de la 
mundialización, los procesos de integración regional y las nuevas formas de autoorganización ciudadana han complejizado este entramado institucional. En su interior, las diferentes instituciones no son departamentos estancos, sino que son interdependientes y están interrelacionadas. Difícilmente puedes transformar nada desde el Estado si las instituciones de la UE o los organismos internacionales que determinan tus políticas y acceso al crédito en el mercado financiero internacional no te lo permiten. O a la inversa. Al igual que tampoco es posible transformar la sociedad intentando crear espacios cooperativas en el espacio de lo social sin aspirar a cambiar un gobierno abiertamente neoliberal. $\mathrm{O}$ a la inversa. Por tanto, la transformación radica en transformar distintos momentos institucionales propios de los diferentes campos de lucha de los derechos (internacional, estatal y comunitario).

La existencia, durante la época de los Estados nacionales soberanos, de un modelo de monismo jurídico implicaba la existencia de un poder vértice en forma de Constitución, que generaba una cadena de validez normativa descendente sistemática, integral y coherente. El Estado constituía un espacio con un único orden jurídico, del que el territorio nacional era el ámbito de validez. Ello hacía que, en su interior, aquella clase o grupo social que conseguía hacerse con el Ejecutivo y el legislativo podía implementar un acto de ruptura por vía del Poder Constituyente, propiciando transformaciones estructurales en cortos periodos de tiempo. Fijémonos en el ejemplo cubano. Tras el triunfo de la Revolución cubana en 1959, el Consejo de Ministros aprobó diferentes leyes de confiscación, de intervención y nacionalización, de manera que al finalizar las nacionalizaciones de 1963, en tan solo cuatro años, la propiedad estatal ocupaba en Cuba el $95 \%$ de la industria, el $98 \%$ de la construcción, el $95 \%$ del transporte, el $70 \%$ de la agricultura, el $75 \%$ del comercio minorista y el $100 \%$ del comercio mayorista.

Sin embargo, fruto de los procesos neoliberales de integración regional (Unión Europea) y mundial (Organización Mundial del Comercio, Banco Mundial, Fondo Monetario Internacional, etc.), entre otros procesos de complejización del entramado institucional que media el ejercicio del poder, hace que el antiguo modelo de monismo jurídico existente en el interior de los Estados haya sido sustituido por un modelo de pluralismo jurídico o coexistencia de legislación estatal con las normas creadas por los organismos tecnocráticos internacionales. Ello da lugar al solapamiento, en el interior del territorio estatal, de múltiples entramados institucionales y ordenamientos jurídicos provenientes de autoridades diferentes que pretenden imponer su influencia sobre el mismo territorio y sujetos, muchas veces de manera conflictiva entre ellos. De esta manera, detentar el control del Ejecutivo no te garantiza que puedas transformar nada y, sino, que se lo pregunten a Syriza en Grecia. Antes hacía referencia a ello.

$Y$, en segundo lugar, la existencia de distintos sujetos colectivos que se construyen sobre lazos, identidades o bases de solidaridad colectiva muy distintos (intereses económicos, de género, territoriales, de raza, etc.) significa que para cada uno de ellos la explotación y la dominación se da de manera distinta y, en consecuencia, la emancipación también significa cosas distintas. Mientras para unos la emancipación será el fin de la familia normativa heteropatriarcal, para otros será la nacionalización de su fábrica. Y, sin embargo, en tanto que se trata de una cuestión subjetiva, no objetiva, resulta difícil poder jerarquizar entre emancipaciones más 0 menos importantes.

En este contexto, la vieja idea de revolución del s. XX entendida como asalto por parte de un sujeto histórico universal con un único programa político a una institución (el Gobierno) para, a través de un golpe de efecto, dar la vuelta al orden socio-económico en un corto periodo de tiempo, no tiene ningún sentido. Entre otras 
cosas porque, como hemos explicado, aunque accedas al gobierno, hoy, no detentas la juridicidad o la posibilidad de imponer las normas jurídicas que quieras. Por ello la dicotomía en nuestra sociedades ya no es "revolución vs. reforma», en el sentido clásico de estos conceptos, sino, como diría Enrique Dussel (2006), ahora es «trasformación vs. reforma». Y la transformación ya no será un acontecimientoruptura protagonizado por un sujeto, sino que solo puede ser un proceso múltiple de transformación de distintos espacios y momentos institucionales en los distintos campos de lucha de los derechos, llevado a cabo por sujetos diversos, en el marco de un proceso conflictivo largo y constante de cambio. De ahí lo de reformismo revolucionario o revolución reformista, en tanto que se trata de una transformación estructural (elemento propio de la revolución del s. XX), pero de larga temporalidad (elemento propio del reformismo del s. XX).

Pero claro, el hecho de que el profesor Ricardo Cueva se niegue a aceptar la complejización del espacio sociopolítico o del entramado institucional que intermedia el ejercicio del poder de nuestras sociedades (para él seguimos viviendo en una sociedad parecida a la de la revolución industrial), así como la existencia de una pluralidad y fragmentación de sujetos colectivos que califica de exagerada y poco apegada a la realidad hace que, para él, esta hibridación entre los conceptos clásicos de revolución y reforma que acabamos de explicar sea un oxímoron incomprensible. Parece seguir anclado en el monoteísmo liberal que solo entiende la revolución y la reforma como una contradicción binómica imposible de conciliar, acusando a quien lo hace de «navegar entre ambigüedades» y «no tener temor al oxímoron».

La verdad es que al rechazar que no puede haber otro sujeto que el único universal de la revolución industrial y al entender la revolución y la «radicalidad» en el sentido que se atribuía a éstas en el s. XX, da la sensación que a Cueva Fernández no quiere aceptar que nuestra sociedad ha cambiado y se ha complejizado, viviendo anclado a mitad del siglo XX y no en el 2020.

En resumen, el recurso a lo posmoderno, en genérico, como forma automática de desacreditación; la identificación de la pluralidad de sujetos como «negrismo» o «laclaunismo», sin diferenciar entre ellos; la creencia de que la estructura social de clases de la vieja sociedad industrial no ha cambiado; la acusación de socialista utópico a las posturas que no defienden la planificación centralizada estatal; la imposibilidad de ver la relación entre revolución y reforma más allá de una contradicción binaria imposible de conciliar, etc. son elementos que, voluntaria o involuntariamente, parecen estar reproduciendo los argumentos básicos de la ortodoxia comunista frente a la heterodoxia planteada en el libro.

\section{Bibliografía}

Aglietta, M. (1976). Regulación y crisis del capitalismo. Madrid, España: Siglo XXI.

Arriola, J. (2016). El debate sobre el euro y la soberanía económica: ¿salir del euro sin salir del capitalismo? Dossiers de Ruptura, Núm. 2.

Boyer, R. (1992). La teoría de la regulación. Un análisis crítico. Valencia, España: Edicions Alfons el Magnànim.

Correas, O. (2003). Acerca de los Derechos Humanos. Apuntes para un ensayo. Ciudad de México, México: Ediciones Coyocacán.

Correas, O. (2013). Introducción a la crítica del derecho moderno. Ciudad de México, México: Fontamara. 
Cueva, R. (2020). ¿Una «tercera vía» en el constitucionalismo? Comentario a Albert Noguera, La ideología de la soberanía. Hacia una reconstrucción emancipadora del constitucionalismo. Eunomía. Revista en Cultura de la Legalidad, 19, pp. 545551.

Dussel, E. (2006). 20 tesis de política. México: Siglo XXI.

Franzius, C. (2003). Der Gewährlesitungsstaat ein neues Leitbild für den sich wandelnden Staat? Der Staat, 42(4), pp. 493-517.

Hardt, M. y Negri, T. (2004). Multitud. Guerra y democracia en la era del imperio. Barcelona, España: Debate.

Hobbes, T. (2000). De Cive. Madrid, España: Alianza.

Karatani, K. (2005). Transcritique. Cambridge-Massachussets, USA: MIT Press.

Lipietz, A. (1986). Behind the crisis: the exhaustion of a regime of accumulation. A regulation school perspective on some French empirical works. Review of Radical Political Economics, 18(1-2), pp. 13-32.

Martín, S. (2020). Nuevo mapa conceptual para el constitucionalismo crítico. Comentario a Albert Noguera, La ideología de la soberanía. Hacia una reconstrucción emancipadora del constitucionalismo. Eunomía. Revista en Cultura de la Legalidad, 19, pp. 552-578.

Marx, K. y Engels, F. (1955). La guerra civil en Francia. En Obras escogidas (2 vols) (Vol. 1., pp. 491-571). Moscú, URSS: Progreso. Ediciones en lenguas extranjeras.

Noguera, A. (2017). El sujeto constituyente. Entre lo viejo y lo nuevo. Madrid, España: Trotta.

Noguera, A. (2019). La ideología de la soberanía. Hacia una reconstrucción emancipadora del constitucionalismo. Madrid, España: Trotta.

Rousseau, J.J. (1970). El contrato social. En Scritti politici. A cura de paolo Alatri, Torino, Italia: Utet.

Saad-Filho, Alfredo (2010). Crisis in Neoliberalism or Crisis of Neolib- eralism? En L. Panitch, G. Albo and V. Chibber (Eds), Socialist Register 2011: The Crisis This Time (pp. 242-259), Londres, Gran Bretaña: The Merlin Press.

Sanabria, A. (2014). L'euro no és l'ajust. En VV.AA. Cap a la independencia económica: necessitem sortir de l'euro? Documents per al debat CUP, 2, pp. 1934.

Schoch, F. (2008). Gewährleistungsverwaltung: Stärkung der Privatrechtsgesellschaft? Neue Zeitschrift für Verwaltungsrecht, 3, pp. 241-247.

Spinoza, B. (1986). Tractatus theologico-politicus.Madrid, España: Alianza.

Tapia, L. (2017). Marxismo transcrítico. La Paz, Bolivia: Autodeterminación.

Vesting, T. (2000). Zwischen Gewährleistungsstaat und Minimalstaat. En Verwaltungsrecht in der Informationsgesellschaft (pp. 101-131). Munich, Alemania: Beck.

Von Pufendorf, S. (1943). De iure naturae et Gentium. En Principi di diritto naturale. A cura di Norberto Bobbio, Torino, Italia: Paravia. 